\title{
Effect of Crankcase Blow-by on Particle Emission of Internal Combustion Engine
}

\author{
Xiao-Jun $\mathrm{XU}^{1, \mathrm{a}}$, Jun $\mathrm{LI}^{1, \mathrm{~b}}$ and Lu-Yan $\mathrm{FAN}^{1, \mathrm{C},{ }^{*}}$ \\ ${ }^{1}$ College of Automotive Engineering, Jilin University, China \\ a 1764017812@qq.com, b junli610@163.net, c fanluyan@163.com \\ ${ }^{*}$ Corresponding author: Lu-Yan FAN
}

\begin{abstract}
Keywords: Internal combustion engine, Blow-by of crankcase, Particle emission, Number concentration
\end{abstract}

\begin{abstract}
By controlling the flow of crankcase blow-by to atmosphere or intake system, number concentration of particle distribution was measured in a diesel engine and a gasoline direct injection engine (GDI engine). The effect of blow-by on particle emission was investigated in different conditions. EEPS ${ }^{\mathrm{TM}}$ (3090) exhaust particle spectrometer and exhaust dilution and measurement \& control system were used in those tests. The results show that leading blow-by of crankcase into the intake system increases the particle number concentration peak value and develops new concentration peak area. For the diesel engine, blow-by mainly affects the concentration distribution of nuclei model particle and the accumulation mode particle less than 100nm; for the gasoline GDI engine, blow-by of crankcase mainly affects the concentration distribution of nuclei model particle. In addition, taking blow-by of crankcase into intake system leads to the increase in the total number concentration of particle in all conditions. For the diesel engine, the increase of total number concentration in the condition of middle and high amount of blow-by are $44.2 \%$ and $38.5 \%$; for the gasoline GDI engine, the increase of total number concentration in the condition of low blow-by leakage reaches up to $93.8 \%$.
\end{abstract}

\section{Introduction}

In the normal operation of the internal combustion engine, part of unburned combustible mixture and exhaust gas in the cylinder would get in to crankcase through clearances. These clearances include piston ring side clearance, the clearance between cylinder and piston ring, the clearance between piston ring and rind grooves. In the crankcase, there would be some lubrication oil mist because of splash and lubrication oil vapor because of high temperature. So the lubrication oil mist and the lubrication oil vapor would mix with the gas from the cylinder. Finally it would become blow-by of crankcase [1-2]. Row blow-by of crankcase would pollute the air if it was led to the atmosphere directly. The current emission regulations had made it clear that the internal combustion engine must use closed positive crankcase ventilation system. That is to say blow-by of crankcase should be led into cylinder and burn it again [3-4]. It would avoid direct pollution to the atmosphere, but it would also trigger a series of new problems. Most serious of all is that burning blow-by of crankcase would generate a lot of particle. The particle would make internal combustion engine after-treatment more difficult. What's more nanometer particle would do harm to our body [5-7]. So it makes litter sense to analysis the pollution of blow-by of crankcase, a new way must be found to evaluate the effect of crankcase blow-by on particle emission. This paper studied variation of the number concentration distribution of exhaust particle in internal combustion engine by controlling the flow of the blow-by of crankcase. In one case the flow of the blow-by was led into the atmosphere, in the other case it was led into the intake system. The experiment was made in a diesel 
engine and a GDI gasoline engine by using engine bench. In this way we can have a quantitative analysis of the effect of the blow-by on particle emission.

\section{Test Equipment and Method}

\section{Test Equipment}

A 2.0L diesel engine and a 1.4L gasoline engine were used, and technical parameters of the internal combustion engine are shown in Table 1.

Tab.1 Technical parameters of the test engines

\begin{tabular}{|c|c|c|}
\hline Engine & 2.0L diesel engine & 1.4L gasoline engine \\
\hline Type & $\begin{array}{l}\text { Inline four cylinders, } \\
\text { Turbocharged inter-cooled }\end{array}$ & $\begin{array}{l}\text { Inline four cylinders, } \\
\text { Turbocharged inter-cooled }\end{array}$ \\
\hline Fuel System & $\begin{array}{l}\text { Electronically control high } \\
\text { pressure common rail }\end{array}$ & Direct-injection \\
\hline $\begin{array}{l}\text { Cylinder Diameter } \\
\times \text { stroke }[\mathrm{mm}]\end{array}$ & $83.1 \times 92.0$ & $76.5 \times 75.6$ \\
\hline Compression Ratio & $16.7: 1$ & $10: 1$ \\
\hline $\begin{array}{l}\text { Engine Rated Power } \\
{[\mathrm{Kw}]}\end{array}$ & 110 & 96 \\
\hline $\begin{array}{l}\text { Rated Power Speed } \\
{\left[\mathrm{r} \cdot \mathrm{min}^{-1}\right]}\end{array}$ & 4000 & 5000 \\
\hline Max Torque $[N \cdot m]$ & 310 & 250 \\
\hline $\begin{array}{l}\text { Maximum Torque } \\
\text { Speed }\left[\mathrm{R} \cdot \mathrm{Min}^{-1}\right]\end{array}$ & $1800-2800$ & $1750-3000$ \\
\hline
\end{tabular}

The particle size measuring instrument used in the tests is produced by TSI company, and it is called EEPS $^{\mathrm{TM}}$ (3090) Internal combustion engine exhaust particle size spectrometer, technical parameters are shown in the Tabel2 [8].

Tab.2 Parameters of exhaust particle spectrometer

\begin{tabular}{ll}
\hline Type & $\operatorname{EEPS}^{\mathrm{TM}}(3090)$ \\
\hline Particle Size Resolution & 16 channel /10 times particle size \\
Channel Number & 32 channel \\
Measurement Mode & $\begin{array}{l}\text { Simultaneous measurement of multiple } \\
\text { electrometer }\end{array}$ \\
Sampling Frequency & $10 \mathrm{~Hz}$ \\
Particle Size Measurement Range & $5.6-560 \mathrm{~nm}$ \\
Concentration Measurement Range & $10^{3} \sim 10^{7}$ \\
\hline
\end{tabular}


When the exhaust gas sample was tested, we have to dilute it in order to protect particle size spectrometer [9]. So two stage level dilution method was used in this series of test. A partial flow dilute method was used in the first stage dilution, and full flow dilution was used in second stage dilution. The dilution ratio of the system can be calculated and controlled by measuring the concentration of $\mathrm{CO}_{2}$ before and after dilution [10].Figure 1 shows the exhaust gas dilution and measurement \& control system. Figure 2 is a physical map of the internal combustion engine test benche.

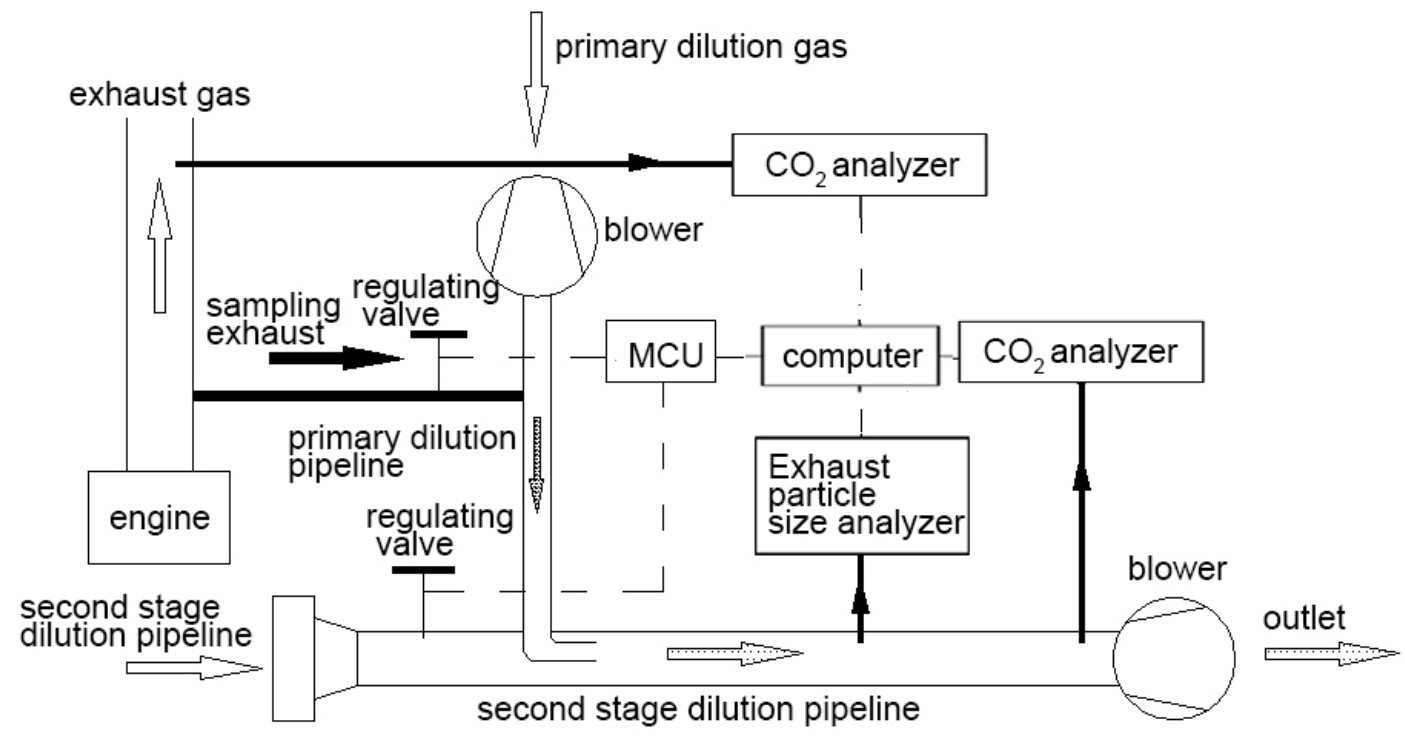

Fig.1 Exhaust gas dilution and measurement \& control system

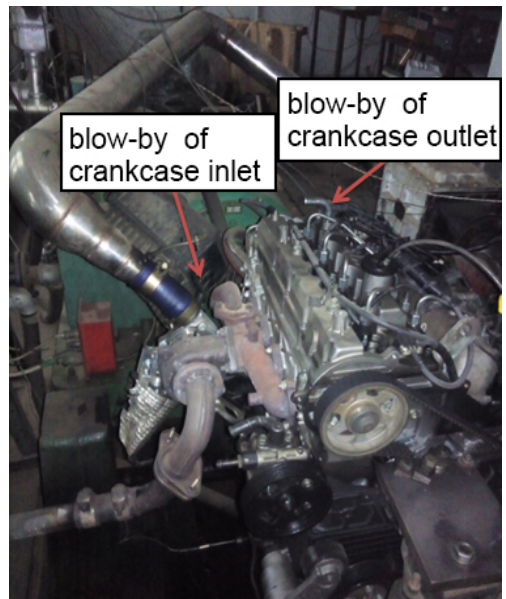

(a) Diesel engine test bench

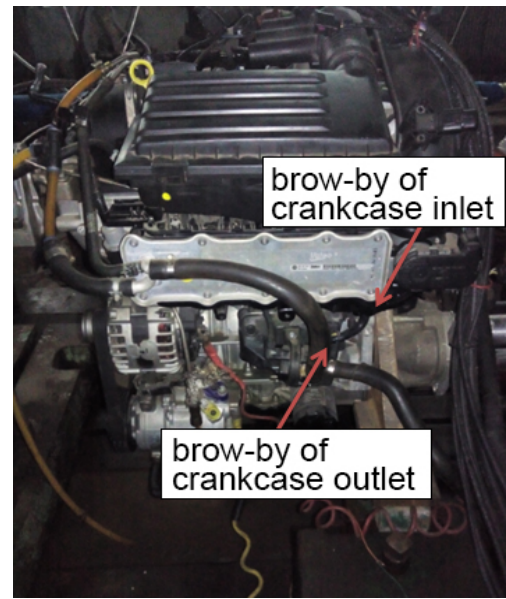

(b) GDI gasoline engine test bench

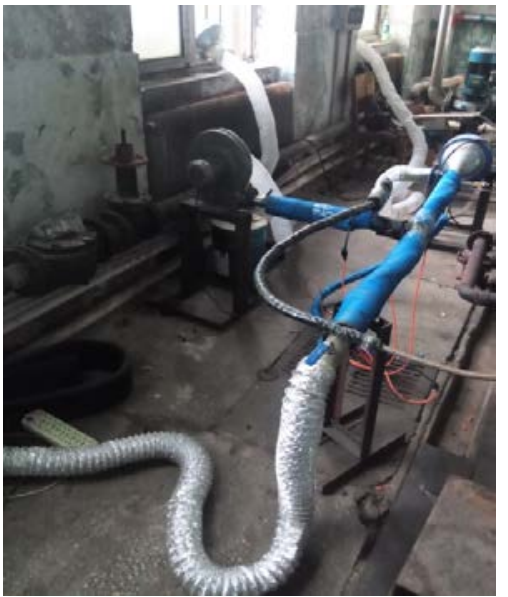

(c) exhaust gas particle two stage dilution system

Fig.2 Internal combustion engine test bench

\section{Test Method}

This study was carried out on the diesel engine and GDI gasoline engine respectively. The test conditions of the internal combustion engine were chose according to amount of blow-by of crankcase .Table 3 shows various test conditions of the engine, corresponding to the small, medium and large amount of blow-by of crankcase. 
Tab.3 Test conditions and the amount of blow-by

\begin{tabular}{cccc|cccc}
\hline \multicolumn{4}{c}{ Diesel engine } & \multicolumn{4}{c}{ Gasoline engine } \\
\hline Condition & Speed & Torque & Blow-by & Condition & Speed & Torque & Blow-by \\
& {$\left[\mathrm{r} \cdot \mathrm{min}^{-1}\right]$} & {$[\mathrm{N} \cdot \mathrm{m}]$} & {$\left[\mathrm{L} \cdot \mathrm{min}^{-1}\right]$} & & {$\left[\mathrm{r} \cdot \mathrm{min}^{-1}\right]$} & {$[\mathrm{N} \cdot \mathrm{m}]$} & {$\left[\mathrm{L} \cdot \mathrm{min}^{-1}\right]$} \\
1 & 1400 & 50 & 31.6 & 1 & 1000 & 60 & 8.3 \\
2 & 2000 & 150 & 53.5 & 2 & 2000 & 160 & 12.4 \\
3 & 2500 & 230 & 73.4 & 3 & 3000 & 200 & 15.2 \\
\hline
\end{tabular}

Firstly, the engine was adjusted to a target condition, and the blow-by of crankcase was led to atmosphere. When the engine condition was stable, the diameter of particle-number concentration distribution of particle distribution in the secondary dilution pipeline shown by exhaust particle size spectrometer was recorded. According to the real-time $\mathrm{CO}_{2}$ dilution ratio the number concentration of particle in the exhaust gas was calculated. Secondly, the blow-by of crankcase was led into intake pipe in the same condition. After the internal combusting engine has been run for three minutes, the diameter of particle-number concentration distribution of particle distribution was recorded again. According to the real-time $\mathrm{CO}_{2}$ dilution ratio, the number concentration of particle in the exhaust gas was calculated. Finally, the results were compared with the previous ones. (Attention: the sample from diesel engine needs a larger dilution ratio due to the high concentration of particle, the sample from gasoline engine needs a smaller dilution rate because the concentration of particle is not so high.)

\section{Results and Analysis}

\section{Influence of Diesel Engine's Blow-by of Crankcase on Particle Emission}

Figure 3 shows contrast map of diameter of particle-number concentration distribution of particle in different conditions in diesel engine. The abscissa indicates the particle diameter $d_{p}$, and the ordinate indicates the number of particle per $\mathrm{cm}^{3} \mathrm{dN}$. It can be seen from the figure, when the blow-by of crankcase was led into intake pipe, it mainly affected the number concentration distribution of particle of 5 100nm. If the blow-by of crankcase was led into intake pipe it increased the number of particle in all conditions. When the amount of blow-by was small, the concentration of particle increased significantly, and it increased more obviously when the amount of blow-by was medium or large. In some conditions, the peak area of the particle concentration would change, if blow-by of crankcase was led into intake pipe. In some cases, it promoted the formation of new peek areas.

When the diesel engine worked under the condition of $1400 \mathrm{r} \cdot \mathrm{min}^{-1}, 50 \mathrm{~N} \cdot \mathrm{m}$ and the blow-by of crankcase was led to the atmosphere directly, the number concentration of particle in the exhaust gas was bimodal, and the peak regions were $6 \sim 10 \mathrm{~nm}$ and $30 \sim 50 \mathrm{~nm}$. If the blow-by of crankcase was led to intake pipe, the number concentration of particle showed a bimodal distribution. and the peak regions were 15 20 nm and 25 45 nm. In the second condition, bimodal peak value increased by $174.6 \%$ and $124.2 \%$ respectively, and the total number of particle increased by $107.1 \%$. The number of nuclei model particle with a diameter of 10 to $50 \mathrm{~nm}$ was significantly increased when the blow-by of crankcase was led into intake pipe. The reason for the difference is that the lubrication oil in the blow-by of crankcase affected the combustion of the engine and promoted the formation of the particle [11-12]. It has to format a nuclear, then grows, and finally oxidizes to 
format a particle. When the blow-by of crankcase was led to atmosphere, incomplete burned fuel oxidized cleavage, and then it formed a nuclei modal particle core. Unburned HC in the cylinder adsorbed on its surface to promote particle growth. The particle collapsed together to form accumulation mode particle, and finally the particle had a bimodal distribution[13]. When the blow-by of crankcase was led into the intake pipe, if the engine worked at low speed and low load condition, the temperature of cylinder would be low and air movement would be weak. So part of lubrication mist in the blow-by was not burned completely, and it generated more nuclei modal particles in the cylinder. Part of lubrication oil was not burned and it would adsorb on the surface of the particle to promote its further growth in the exhaust progress. So if the amount blow-by was small, number of particle peak would gather to $15 \sim 45 \mathrm{~nm}$.

When the diesel engine worked under the condition of $2000 \mathrm{r} \cdot \mathrm{min}^{-1}, 150 \mathrm{~N} \cdot \mathrm{m}$ and the blow-by of crankcase was led to the atmosphere, the number concentration of particle in diesel engine exhaust gas showed a single peak distribution and the peak area was $25 \sim 60 \mathrm{~nm}$. When the blow-by of crankcase was led to intake pipe, the number concentration of particle showed a bimodal distribution, and the peak areas were $9 \sim 12 \mathrm{~nm}$ and 50 100nm. The number of nuclei modal particle of $9 \sim 12 \mathrm{~nm}$ and number of accumulation mode particle of $50 \sim 120 \mathrm{~nm}$ increased significantly. When the blow-by of crankcase was led to atmosphere, with the engine speed and load increased, the cylinder temperature rose. The core of nuclear mode particle with small size was rapidly oxidized and the high exhaust gas temperature also inhibited the process of HC condensation. So the number of nuclei modal particles with small size would decrease, and the number concentration of particle would show a single peak distribution. It is worth noting that in this case the nuclear mode particle was generated mainly due to incomplete combustion. When the blow-by of crankcase was led to intake pipe, with the engine speed and load increased, the temperature of lubrication and the pressure of the crankcase would increase. So the amount of blow-by would increase, and there would be more lubrication mist rush into the cylinder. Formation velocity was greater than the oxidation velocity for nuclei mode particle. The number of nuclei modal particles with small size would increase, and lubrication unburned would adsorb on its surface to promote growth of particle. In this way, the number of accumulation mode particle would increase, and the peak area moved to large particle size. If the amount of blow-by was medium, when the blow-by of crankcase was led to crankcase, both of the accumulation mode particle and nuclei model particle would increase significantly.

When the diesel engine worked under the condition of $2500 \mathrm{r} \cdot \mathrm{min}^{-1}, 230 \mathrm{~N} \cdot \mathrm{m}$ and the blow-by of crankcase was led to the atmosphere, the number concentration of particle in the diesel engine exhaust gas showed bimodal distribution, the peek region was 8 12nm and 25 50nm. When the blow-by of crankcase was led to intake pipe, the number concentration of particle in diesel engine exhaust gas showed bimodal distribution, the peak regions are $8 \sim 15 \mathrm{~nm}$ and $30 \sim 60 \mathrm{~nm}$ and the nuclei modal particle of 15 50nm increased significantly. The high peak value increased by $47.0 \%$ and the total number of particle increased by $38.5 \%$ compared to leading blow-by of crankcase directly to the atmosphere. With the increase of diesel engine speed and load, the increase of the temperature in the cylinder was beneficial to oxidize the core of nuclear mode particles. However the combustion time was shortened, the unstable combustion increased, the generation velocity of nuclear mode particle with small size was faster than that of oxidation velocity. So when the blow-by of crankcase was led to atmosphere, it turned out to be a peak area of small nuclei modal particles. When the blow-by of crankcase was led to intake pipe, with the engine speed and load increase, the temperature of lubrication and the pressure of the crankcase would increase. So the amount of blow-by would increase, and there would be more lubrication mist rush into the cylinder. 
This would deteriorate combustion, the high temperature and strong airflow in the cylinder increased the frequency of inter-particle collision. In this way, it would promote the polymerization of small nuclei model particles but it could not form stable large accumulation mode particles. The number of nuclear model particle with diameter range from 15 50nm would increase significantly but the number of nuclear model particle with diameter less than $15 \mathrm{~nm}$ and the number of accumulation mode particles did not change too much.

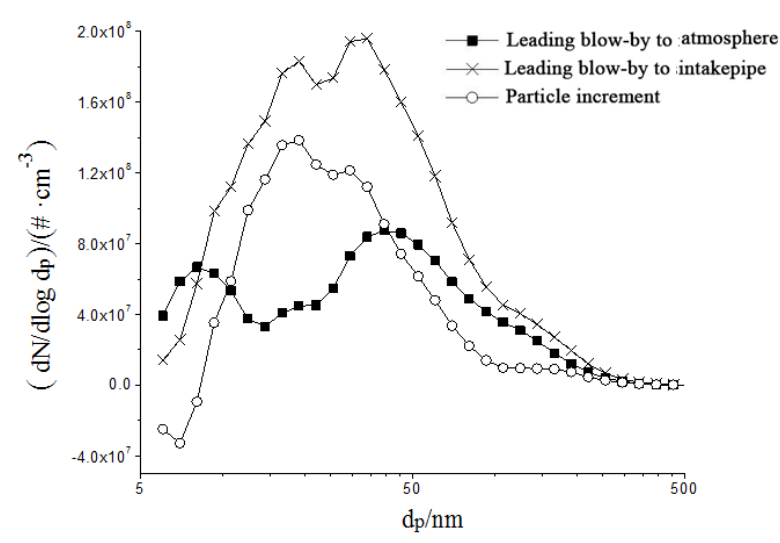

(a) $1400 \mathrm{r} \cdot \mathrm{min}^{-1}, 50 \mathrm{~N} \cdot \mathrm{m}$

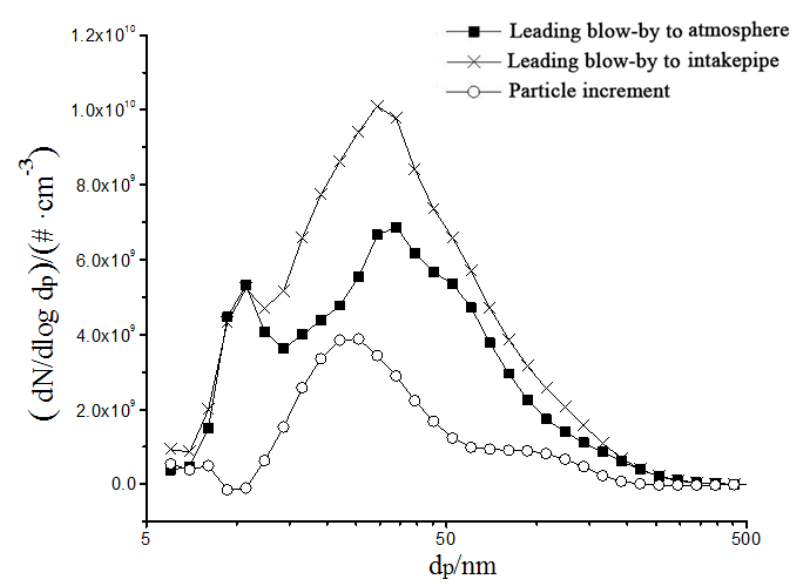

(c) $2500 \mathrm{r} \cdot \mathrm{min}^{-1}, 230 \mathrm{~N} \cdot \mathrm{m}$

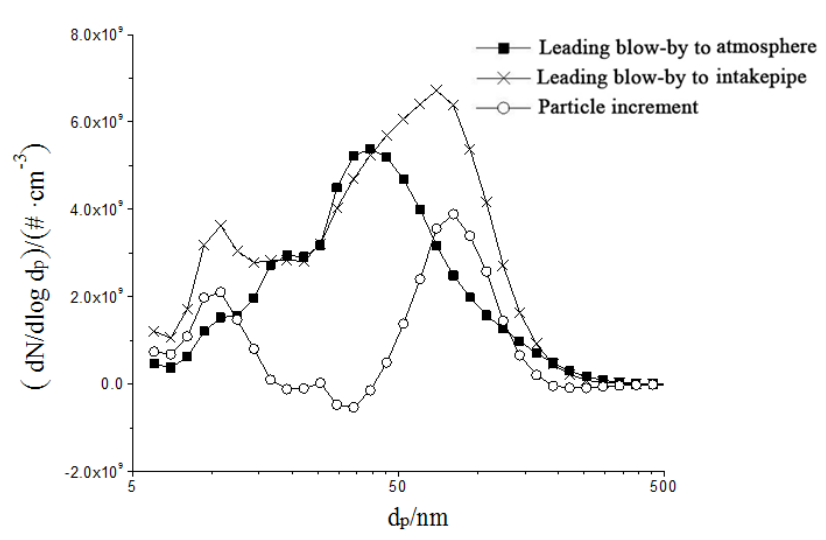

(b) $2000 \mathrm{r} \cdot \mathrm{min}^{-1}, 150 \mathrm{~N} \cdot \mathrm{m}$

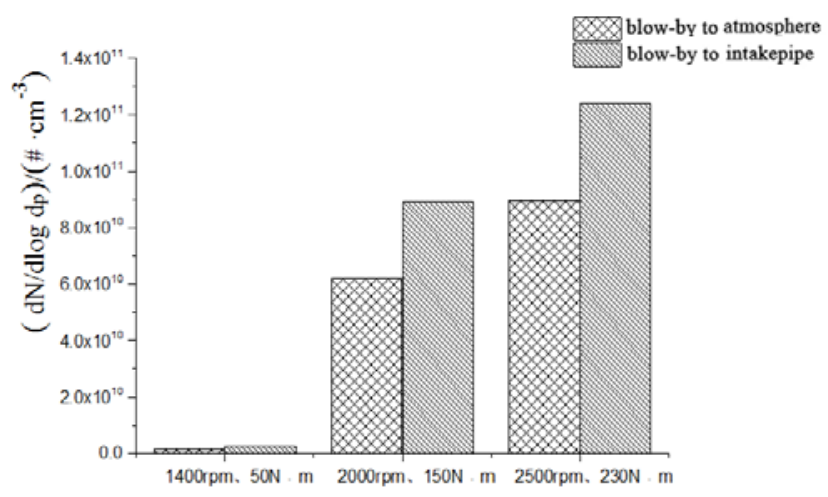

(d)Comparison of the total amount of particle in each condition

Fig.3 contrast map of diameter of particle-number concentration distribution of particle in different conditions in diesel engine

\section{Effect of GDI Gasoline Engine's Blow-by of Crankcase on Particle Emission}

Figure 4 shows contrast map of diameter of particle-number concentration distribution of particle in different conditions in GDI gasoline engine in different test conditions. In one test condition the blow-by of crankcase was led to atmosphere, in other condition, the blow-by of crankcase was led to intake pipe. The abscissa indicates the particle diameter $d_{p}$, and the ordinate represents the number of particle per $\mathrm{cm}^{3} \mathrm{dN}$. If the blow-by of crankcase was led into intake pipe, as the figure shows, it mainly affected the number concentration distribution of nuclei modal particle with diameter ranging $5 \sim 50 \mathrm{~nm}$. On one hand, the total number of particle increased in all conditions, but if the amount of blow-by was small, it would increase more significantly. On the other hand, it would promote the formation of new number concentrations of peak areas in some conditions. 
When the gasoline engine worked under the condition of $1000 \mathrm{r} \cdot \mathrm{min}^{-1} 60 \mathrm{~N} \cdot \mathrm{m}$ and the blow-by of crankcase was led into the atmosphere directly, the number concentration of particle in exhaust gas showed bimodal distribution, the peek regions were 6 12nm and 30 50nm. Most of the particle were mainly concentrated in the peak area of $6 \sim 12 \mathrm{~nm}$. When the blow-by of crankcase was led into intake pipe, the number concentration of particles in exhaust gas showed bimodal distribution. The peak regions were $6 \sim 12 \mathrm{~nm}$ and $35 \sim 50 \mathrm{~nm}$. Compared to the first case, the nuclei modal particle of $6 \sim 12 \mathrm{~nm}$ would increase significantly, the high peak value would increase by $98.6 \%$, and the total number of particle would increase by $93.8 \%$. Due to the uneven mixture of oil and air in the cylinder, the emission of particulate is higher ,especially in cold start and low load condition[14-15].When the blow-by of crankcase was led to the atmosphere, due to uneven combustion in cylinder, a large number of unburned HC condensed in the exhaust gas to form nuclei mode particle, some of particle would collide with each other and form larger nuclei model particle. The number concentration of particle showed bimodal distribution, and most of the particle was nuclear model particle with small size. When the blow-by of crankcase was led into intake pipe, the lubrication oil would be discharged as unburned HC directly. It would make the number of particle of increase. So if the flow of blow-by of crankcase was small, the lubrication oil would promote the emission of nuclear model particle.

When the gasoline engine works under the condition of $2000 \mathrm{r} \cdot \mathrm{min}^{-1}, 160 \mathrm{~N} \cdot \mathrm{m}$ and the blow-by of crankcase was led to the atmosphere directly, the number concentration of particle showed bimodal distribution, the peek region were $9 \sim 14 \mathrm{~nm}$ and $30 \sim 60 \mathrm{~nm}$. Most of the particle were mainly concentrated in the 30 60nm peak area. When the blow-by of crankcase was led to the intake pipe, the number concentration of particles showed single peak distribution and the peak area was $20 \sim 60 \mathrm{~nm}$. The peak value increased by $33.7 \%$ and the total number of the particle was increase by $29.0 \%$. With the increase of engine load and temperature of cylinder, combustion condition improved, most of the nuclei model particle would be oxidized in at the later stage. Volatiles were not easy to condense because of high temperature, so the number of nuclei model particle would decrease compared to small load condition. When the blow-by of crankcase was led to intake pipe, the lubrication oil mist would promote the growth of nuclear mode particle. What's more, the particle would collide with each other and it would promote the formation of particle with large size. The number of particle increased rapidly and showed single peak distribution. Therefore, in the case of medium amount of blow-by, the lubrication oil in the blow-by of crankcase would promote the growth of particle and increase the number of particle.

When the gasoline engine worked under the condition of $3000 \mathrm{r} \cdot \mathrm{min}^{-1}, 200 \mathrm{~N} \cdot \mathrm{m}$ and the blow-by of crankcase was led to the atmosphere directly, the number concentration of particle showed single peak distribution, the peak area was $25 \sim 60 \mathrm{~nm}$. When the blow-by of crankcase was led to intake pipe, the number concentration of particle showed bimodal distribution, and the new peak area was $9 \sim 14 \mathrm{~nm}$. The high peak value increased by $47.8 \%$ compared to the first case. The number of nuclei mode particle of $9 \sim 14 \mathrm{~nm}$ and 30 50nm increased significantly, and the total number of particle increased by $49.9 \%$ when the blow-by of crankcase was led to the intake pipe. When the gasoline engine worked under high load condition, Volatiles were not easy to condense because of high temperature, therefore, the core of the nuclei mode particle would be less and the total number concentration of particle would be low. But as the increase of engine speed and temperature of cylinder, the amount of blow-by and lubrication oil mist increased significantly, so the lubrication oil mist became a new source of particle generation. The lubrication mist would promote the generation of the core and the growth of the nuclear mode particle. When the amount of blow-by 
was large, the nuclei model particle with diameter less than 20nm would increase rapidly, and the number concentration of nuclei model particle of $25 \sim 60 \mathrm{~nm}$ would increase.

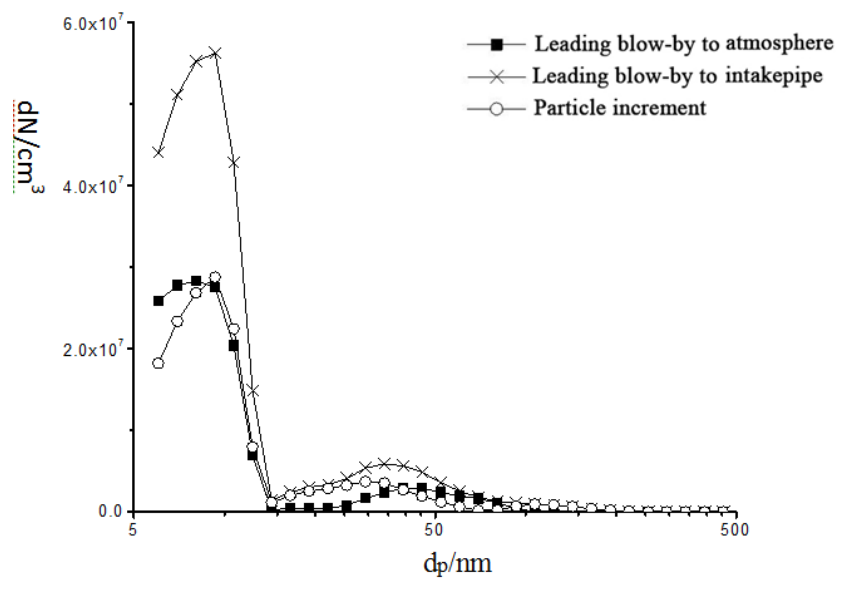

(a) $1000 \mathrm{r} \cdot \mathrm{min}^{-1}, 60 \mathrm{~N} \cdot \mathrm{m}$

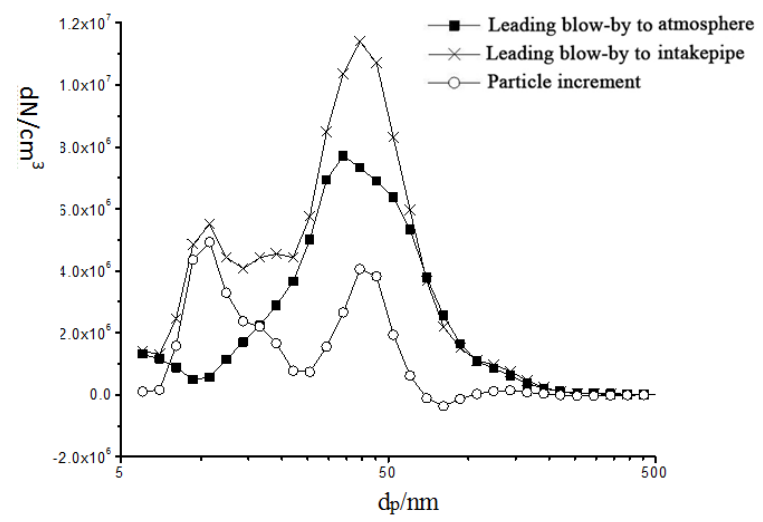

(c) $3000 \mathrm{r} \cdot \mathrm{min}^{-1}, 200 \mathrm{~N} \cdot \mathrm{m}$

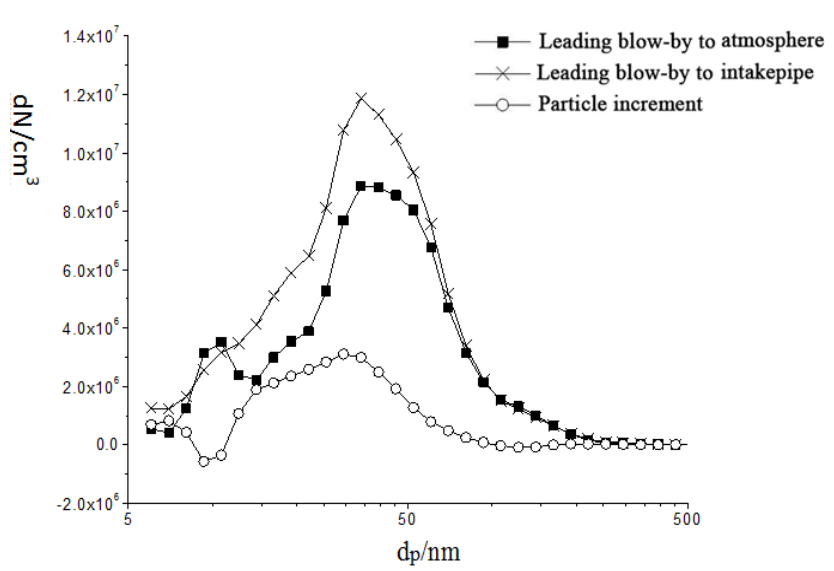

(b) $2000 \mathrm{r} \cdot \min ^{-1}, 160 \mathrm{~N} \cdot \mathrm{m}$

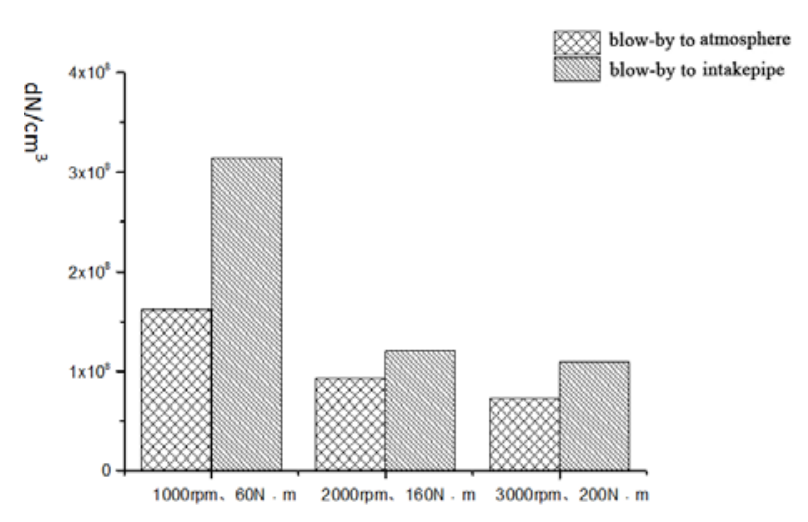

(d) Comparison of the total amount of particle in each condition

Fig.4 Variation of particle number concentration with different blow-by flow direction in several operating conditions for gasoline engine

\section{Conclusion}

1) Leading blow-by of crankcase to the intake pipe would influence number concentration distribution of particle. It was mainly manifested in the increase of peak value and the formation of new peak area. When it comes to diesel engine, it mainly influenced number concentration of nuclei model particle and accumulation mode particle with diameter less than $100 \mathrm{~nm}$. The peak value would increase by $124.2 \%$ when small amount of blow-by was led to intake pipe. The peak value would increase by $12.5 \%$ and a new peak area of nuclei mode particle was found when medium amount of blow-by was led to the intake pipe. The peak value would increase by $47 \%$ when large amount of blow-by was led to intake pipe. When it comes to GDI gasoline engine, the blow-by of crankcase mainly influenced number concentration of nuclei model particle. The peak value would increase by $98.6 \%$ when small amount of blow-by was led to intake pipe. The peak value would increase by $33.7 \%$ when medium amount of blow-by was led to intake pipe. The peak value would increase by $47.8 \%$ and a new peak area of nuclei mode particle was found when large amount of blow-by was led to intake pipe. 
2) The total number of particle in all conditions would increase when the blow-by of crank-case was led to intake pipe. For diesel engine, the number of particle would increase by $107.1 \%$ when the small amount of blow-by was led to intake pipe. The number of particle would increase by $44.2 \%$ when medium amount of blow-by was led to intake pipe. The number of particle would increase by $38.5 \%$ when large amount of blow-by was led to intake pipe. For GDI gasoline engine the total number of particle would increase in all conditions. The number of particle would increase by $93.8 \%$ when small amount of blow-by was led to intake pipe. The number of particle would increase by $29.0 \%$ when medium amount of blow-by was led to intake pipe. The number of particle would increase by $49.9 \%$ when large amount of blow-by was led to intake pipe. So the number of particle increased most significantly when small amount of blow-by was led to intake pipe.

\section{References}

[1] J.Candy, L.Guerbe. Blow-by Gases Coalescing Separation Performances on Passenger Car Engines [J] .SAE Paper 2009-01-0869,2003.

[2] Vivek Kolhe, Manu Sharma, K Veeramani, et al.Development of Advanced Oil Separator to GiveUniform Oil Separation Efficiency across Engine Speed and Load Conditions [J] .SAE Paper2012-01-0179,2012.

[3] Wang Jun. Structure of Blow-by Ventilation System and Its Development Trend[J]. Design \& Manufacture of Diesel Engine, 2012, 18(2):1-8.

[4] Liu Guoli, Liu Zhengyong, Han Junnan,et al. Design and Research of Crankshaft Box System[J]. 2014,(12):17-22.

[5] Kokko J, Rantanen L, Pentikäinen J, et al. Reduced Particulate Emissions with Reformulated Gasoline[R]. SAE Paper2000-01-2017,2000.

[6] Gildemeister A E, Hopke P K, Kim E. Sources of fine urban particulate matter in Detroit, MI[J]. Chemosphere, 2007,69(7):1064-1074.

[7] Wang Xiaodan, Sun Wangchen, Li Guoliang,et al. Effects of Diesel Physical and Chemical Properties on Particle Size Distribution in Common-rail Diesel Engine[J]. Transactions of the Chinese Society for Agricultural Machinery, 2013, 44(11):31-36.

[8] Lai Chunjie, Sun Wangchen, Li Guoliang, et al. Effect of BTL-Diesel Blended Fuel on Emitted Particle Size Distribution Common-Rail Diesel Engine under Transient Conditions[J]. Chinese internal Combustion Engine Engineering, 2012, 33(6):46-57.

[9] Wang Xiaoyan, Li Fang, Ge Yunshan, et al. Particle Size Distribution of Particulate Matter Emission from the Diesel Engine Burning Methanol-diesel Fuel and Biodiesel[J]. Transactions of the Chinese Society for Agricultural Machinery, 2009, 40(8):7-12.

[10]Li Xinling, Huang Zhen,Wang Jiasong, et al. Investigation on Concentrations and Size Distribution Characteristic of Particles from Diesel Engine[J]. Transactions of CSICE, 2007, 25(2):113-117.

[11]Rabute R, Tian T. Challenges involved in piston top ring designs for modern SI engines[J]. Journal of Engineering for Gas Turbines and Power,2001,123(2):448-459. 
[12]Mei Yifan. The Study of Lubricating Oil Consumption from Diesel Engine and Its' Effects on the Formation of PM[D].Tian Jin,Tian Jin University,2011.

[13]Wang Xiaoyan, Li Fang, Ge Yunshan, et al.Particle Size Distribution of Particulate Matter Emission from the Diesel Engine Burning Methanol-diesel Fuel and Biodiesel[J]. Transactions of the Chinese Society for Agricultural Machinery, 2009, 40(8):7-12.

[14]Amin V, Kitae Y, Wagner U, et al. Investigations of the Formation and Oxidation of Soot Inside a Direct Injection Spark Ignition Engine Using Advanced Laser-Techniques[R]. SAEPaper2010-01-0352,2010.

[15]Peckham M S, Price P, Davies M T, et al. Study of Particle Number Emissions from a Turbocharged Gasoline Direct Injection (GDI) Engine Including Data from a Fast-Response Particle Size Spectrometer[R]. SAE Paper2011-01-1224,2011. 